\title{
Turnaround management and blue oceans strategy implementation
}

\section{Karaoulanis Andreas}

andrekaraoul@gmail.com

\section{ABSTRACT}

This paper aims to give the main guidelines for strategic implementation of blue oceans strategy and how this kind of strategy is a part of turnaround management. Also, the author strives to underline the importance of Management Control Systems(MCSs) in this strategy implementation process. The author also briefly examines the importance of cultural expressions inside the company in terms of strategy implementation.

\section{Key Words}

MCSs; Turnaround Management; Blue Ocean Strategy.

\section{Academic Discipline and Sub Disciplines}

Economics; Strategy; Management; Business

\section{Type (Method/Approach)}

Literary Analysis

\section{Council for Innovative Research}

Peer Review Research Publishing System

Journal: Journal of Social Sciences Research

Vol. 9, No. 3

jssreditor.cir@gmail.com

www.jssronline.com 


\section{INTRODUCTION}

A very important question nowadays is, the following:How turnaround/change management can lead to blue ocean creation via the use of the right management control systems (MCSs). This question is very important to be answered because today's global economies and multinational companies are more than ever lean on multicultural personnel, while blue ocean strategies, or turnaround management as some can say, are in need in an uncertain global economic environment like today's.

\section{TURNAROUND/CHANGE MANAGEMENT}

As Kraus et al. (2013) indicated, today's quickly changing economic environment increases the possibility for many companies that during their lifetimes it is probably to face an economic cris is themselves too. If such a situation will take place, companies need to be able to identify the cris is as early as possible in order to devel op the right "weapons" to use and get out of the crisis stronger than before (Hauschild, 2008, cited in Kraus et al., 2013).

According to Eisenhardt et al. (1999), patching is the strategic process by which corporate executives routinely remap businesses to changing market opportunities. This is a crucial process when markets are turbulent (Eisenhardt et al., 1999).

Lenahan $(2006 ; 2011 ; 2005)$, underlined that maintenance is the "sum of activities performed to protect the reliability of the plant", while with the term reliability of a plant, the author implies "a plant that is available when required and capable of performing to designed specification economically and safely for the life of the plant". It is obvious from the above that maintenance is the step which prevents the company from reaching turnaround management.According to Neil Harvey (2011), who quotes Goodman's definition of a tumaround: "A turnaround is to produce a noticeable and enduring improvement in perfomance, to turn around the trend from down to up, from not good enough to clearly better, from under achieving to acceptable, from losing to winning." What springs from that definition is that almost any company can be said that is in a turnaround phase (Andrews, n.d.).

According to Neil Harvey, who quotes Goodman's definition of a turnaround: "A turnaround is to produce a noticeable and enduring improvement in perfomance, to turn around the trend from down to up, from not good enough to clearly better, from under achieving to acceptable, from losing to winning." What springs from that definition is that almost any company can be said that is in a turnaround phase (Andrews, n.d.).

This perspective is in accordance with what Eisenhardt et al. (1999, p. 79)dictates "if senior executives adopt the patching mind- set- in other words, if they assume that organizational change is frequent, routine, and mostly small in scale-and also develop an infrastructure that supports a fluid organization, then they can start to patch as market opportunities arise".

Boyne (2002, cited in Beeri, 2012), classified turnaround management strategies (TMS) into 3 categories (3Rs):

$\checkmark$ Retrenchment strategies which enhance efficiency and stability via selling assets and cutting back on unproductive activities to free up resources that can be re-invested in more productive ones (Boyne, 2006, cited in Beeri, 2012),

$\checkmark$ Repositioning strategies which involve proactive activities that emphasize growth, cost effectiveness and innovation (Robbins and Pearce, 1992; Boyne, 2004, cited in Beeri, 2012),

$\checkmark$ Reorganization strategies which involve replacing key leadership figures, shifting or replacing non - leadership personnel, changing the organizational structure or rethinking the organizational culture (Walshe et al., 2004 , cited in Beeri, 2004).

According to Obiajunwa (2013), there are several skills needed for the successful implementation of turnaround management. The most important of these skills are the following: resource allocation skills, communication/presentation skills, decision making skills, technical and computer knowledge, contract and quality management skills, risk management and human resources skills, budgeting and costmanagement skills, supervision of others skills.

\section{BLUE OCEAN STRATEGY}

According to Kim and Mauborgne (2004),every corporate manager need to realize that the business universe consists of two distinct kind of space, which are the "red" and "blue" oceans. Red oceans represent all the existent industries today, while blue oceans represent the unknown marketspace. The indus tries that meant to be discovered in the future.

As Kim and Mauborgne indicated in their essay "Blue Ocean Strategy" (2004), there are two ways to create blue oceans. Companies can give birth to new market spaces - completely new industries, while, the most common way, is to create a blue ocean from within the existing industry (red ocean) by altering its boundaries. The second case is the one that the author suggests to examine in this $\mathrm{PhD}$ research project.

Kim and Mauborgne (2004), underline that there are 5 elements of the Blue ocean strategy, which are the following:
$\checkmark$ Create uncontested market space
$\checkmark \quad$ Make the competition irrelevant
$\checkmark \quad$ Create and capture new demand
$\checkmark$ Break the value/cost trade off 


\section{ISSN 2321-1091}

$\checkmark \quad$ Align the whole system of a company's activities in pursuit of differentiation and low cost.

As Johnson et al. (2008) indicated in their essay "reinventing your business model", changing in organization level is not an easy thing. In fact the authors are extremely absolute in their opinions when they stated that "pursuing a new business model that's not new or game- changing is a waste of time and money" (Johnson et al., 2008). This underlines of the importance in the creation of something new, a blue ocean, but also indicates how complica ted and difficult this might be.

\section{CULTURAL EXPRESSIONS}

According to LiisaSalo- Lee (2006), "personal and contextual communication styles also are related in cross -cultural studies to individualism and collectivism. Gudykunst and Ting-Toomey (1988, cited in LiisaSalo- Lee, 2006)), suggest these styles also express cultural differences in power distance (hierarchy)". From the above, we can understand that turnaround management implementation can be influenced from several specific cultural characteristics of the personnel of the case company. According to Hofstede et al. (2010) there are several cultural dimensions in societal level which are different between different cultures. As result, Hofstede et al. (2010), developed several patterns of comparis on betwee $n$ different cultures. These patterns are:

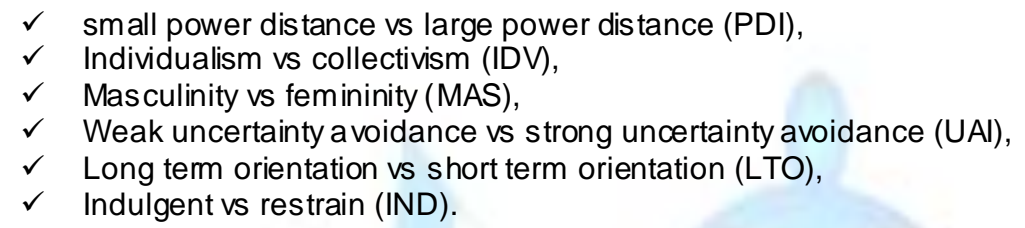

Focusing in uncertainty avoidance, as it is very close to our subject, it is important to underline that according to profess or Andre Laurent (cited in Karaoulanis et al., 2015),

$\checkmark$ Most organizations would be better off if conflicts could be completely eliminated

$\checkmark \quad$ Managers should have precise answers to most questions raised by subordinates about their work

$\checkmark$ For a competent employee to carry out his/hers job properly, precise instructions on how to do it are advised.

$\checkmark \quad$ When roles become complex, detailed job descriptions are a us eful tool for clarification

$\checkmark$ An organizational structure with subordinates having two direct bosses should be avoided at all costs.

It is more than obvious from the above that in order corporate management to implement the right strategy, thus turnaround strategy, is imperative that certain things should be done on organizational level.

\section{MANAGEMENT CONTROL SYSTEMS}

An important aspect of every kind of strategic management, thus turnaround management too, is how it can be implemented. It is the author's prevalent idea that the right Management Control Systems (MCSs) must be implemented in order to help comporate management accomplish its restructuring turnaround management. MCSs are de vices or systems which function via the use of resources (humans, financial etc.) and ensures that the company's objectives are carried out by controlling, encouraging, enabling or forcing employees, in order to perform accordingly to these objectives (Merchant and V.D. Stede, 2012, cited in Karaoulanis, 2015).

According to Neilson et al. (2008), in every strategy execution, besides pay other things motivate individuals to do a good job. This is very important if we can link it with the blue ocean strategy. Corporate management in order to implement a new strategy, need to be able to have the assurance that this strategy will be able to be executed from the company's employees. This is very important because otherwise nothing can be achieved no matter how inspired corporate manager could be. This is an important element in strategy implementation and this link between comporate management and employees is the MCSs as mentioned above.

Ceracal and Stone (2004) underlined the importance of change management as they indicated that change/transformation should be made in a planned and controlled way in order not to get out of control. As executives while transforming their organizations need to take under strong consideration the way their employees will react to such transformations (Ceracal and Stone, 2004), they need to implement the right MCSs in order to be able to control the whole procedure in every possible organizational level.

\section{CONCLUSIONS}

Turnaround management and Blue Oceans strategies are very close related. Especially nowadays when markets are quite turbulent and unstable, companies need to develop such strategies in order to be able to escape from difficult situations and re-form their whole business models. In order to re-form their business, corporate managers need to implement strategies like the "strategy as simple rules" introduced by Eisenhardt et al. (1999) with the use of the right MCSs. In order to be sure that the strategic decisions will be implemented properly, corporate managers need to also take under consideration the cultural behavior and influences coming from personnel, managers and non-managerial staff. The right combination of MCSs and company's culture, especially in big multinationals, can be the foundation upon turnaround management in the form of Blue- Ocean strategies can be implemented with the desired results. 


\section{REFERENCES}

[1] Andrews, n.d., Turnaround Management and Corporate Renewal. University of the Witwatersrand Johannesburg [online]. Available at: <http://www.wits.ac.za/alumni/news/bookreviews/14194/turnaround_html> [Accessed 10 November 2015].

[2]Beeri, I. 2012, "Turnaround Management Strategies in Local Authorities: Not Only for Poor Performers", Local Government Studies, vol. 38, no. 4, pp. 461-483.

[3] Cerasal and Stone, 2004. Business Solutions on Demand: Creating Customer Value at the Speed of Light. Kogan Page Ltd. London UK.

[4] Eisenhardt K.M. \& Brown L. Shona 1999. Patching Restitching Business Portfolios in Dynamic Markets. Harvard Business Review, Volume 77 (3), pp.72-82.

[5] Hofstede G., Hofstede G. J. \&Minkov M., 2010. Cultures and organizations: Software of the mind, New York: McGraw Hill.

[6] Johnson, M.W., Christensen, C.M. \&Kagermann, H. 2008, Reinventing your business model, HARVARD BUSINESS SCHOOL PUBLISHING CORPORATION, WATERTOWN.

[7] Karaoulanis A., 2015. "The Importance of Management Control Systems". Journal of Social Sciences Research, Vol9 (1), pp.1796-1799.

[8] Karaoulanis A., Monfort F., 2015, A comparative study of women in top managerial positions in Greece and the UK. MBA. Blekinge Institute of Technology.

[9] Kim W. Chan, Mauborgne R., 2004. Blue ocean strategy, Harvard Business Review, Vol. 82 (10), pp.76-84.

[10] Kraus, S., Moog, P., Schlepphorst, S. \&Raich, M. 2013, "Crisis and turnaround management in smes: A qualitativeempirical investigation of 30 companies", International Journal of Entrepreneurial Venturing, vol. 5, no. 4, pp. 406-430.

[11] Lenahan, T. 2006;2011;2005;,Turnaround, Shutdown and Outage Management: Effective Planning and Step-by-Step Execution of Planned Maintenance Operations, New ed., Butterworth Heinemann, GB.

[12] LiisaSalo- Lee, 2006. Communication styles. Moniviestin.jiu.fi [online]. Available at: <https://moniviestin.jyu.fi/ohjelmat/hum/viesti/en/ics/20. [Accessed 07 November 2015].

[13]Neil Harvey, Turnaround management and corporate renewal: a South African perspective. Chartered Institute of Management Accountants (CIMA), Wits University Press, Johannesburg: 2011.

[14] Neilson G., Martin K., Powers E., 2008. The secrets to successful strategy execution. Harvard Business Review, Vol.86 (6), pp.60-70.

[15] Obiajunwa, C.C. 2013, "Skills for the management of turnaround maintenance projects", Journal of Quality in Maintenance Engineering, vol. 19, no. 1, pp. 61-73.

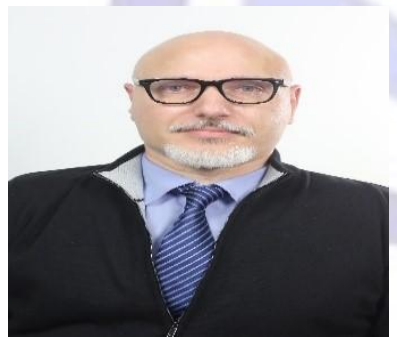

Andreas Karaoulanis, MBA, MsEng is currently working in the banking sector in Greece. He has an MBA degree in Industrial Management and Economics form Blekinge Institute of Technology Sweden and a MSc in Engineering from Aristotle University of Thessaloniki. He is very experienced after 25 years of working in several industries like engineering, banking, retail and consulting. He is a Linked In blogger with many managerial posts. 